Document downloaded from:

http://hdl.handle.net/10251/65566

This paper must be cited as:

Shamzhy, MV.; Opanasenko, MV.; García Gómez, H.; Cejka, J. (2015). Annulation of phenols with methylbutenol over MOFs: The role of catalyst structure and acid strength in producing 2,2-dimethylbenzopyran derivatives. Microporous and Mesoporous Materials. 202:297-302. doi:10.1016/j.micromeso.2014.10.003.

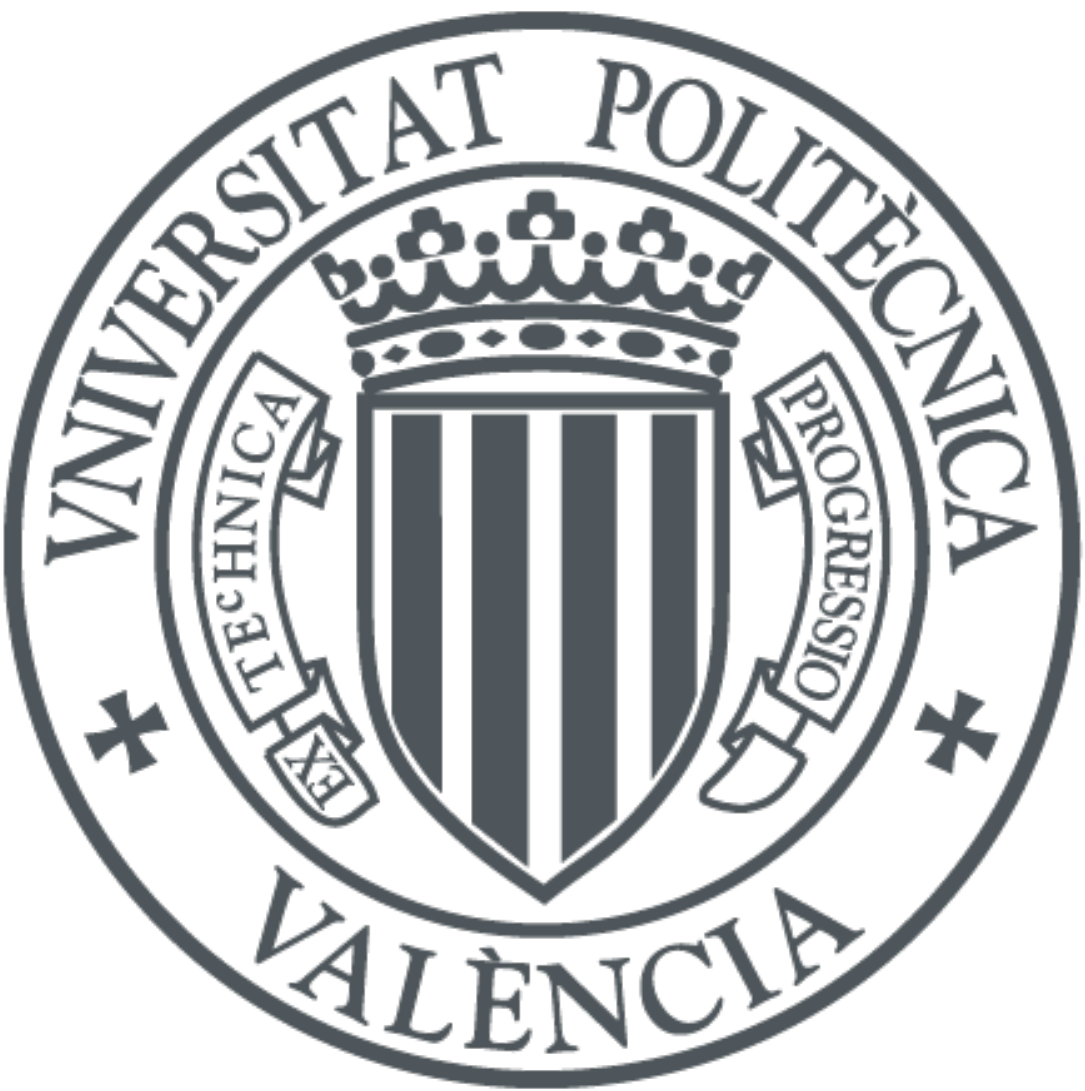

The final publication is available at

http://dx.doi.org/10.1016/j.micromeso.2014.10.003

Copyright Elsevier

Additional Information 


\title{
Annulation of phenols with methylbutenol over MOFs: the role of catalyst structure and acid strength in producing 2,2-dimethylbenzopyran derivatives
}

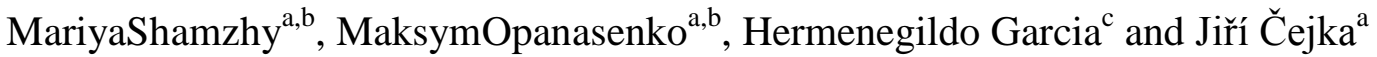

${ }^{a}$ J. Heyrovský Institute of Physical Chemistry, Academy of Sciences of the Czech Republic, v.v.i., Dolejškova 3, CZ-182 23 Prague 8, Czech Republic

${ }^{\mathrm{b}}$ L.V. Pisarzhevskiy Institute of Physical Chemistry, NationalAcademy of Sciences of Ukraine, pr. Nauky, 31, Kyiv03028, Ukraine

'Instituto Universitario de Tecnología Química CSIC-UPV and Departamento de Química Universidad Politécnica de Valencia Av. De los Naranjos s/n, 46022 Valencia, Spain

\begin{abstract}
The catalytic behavior of metal-organic frameworks of different structures (Fe(BTC), MIL-100 $(\mathrm{Fe})$, MIL-100(Cr) and $\left.\mathrm{Cu}_{3}(\mathrm{BTC})_{2}\right)$ was investigated in annulation reaction between 2-methyl-3buten-2-ol and phenols differing in size (phenol, 2-naphthol). The highest conversions of phenols(45 and $75 \%$ after 1300 min of TOS for phenol and 2-naphthol, respectively) and selectivity (45 and $65 \%$ at $16 \%$ of phenol and 2-naphthol conversion, respectively) to target benzopyran were achieved over MIL-100 (Fe) possessing intermediate Lewis acidity, perfect crystalline structure, and the highest $\mathrm{S}_{\mathrm{BET}}$ surface area. The increasing strength of Lewis acid centers for MIL-100(Cr) was found to result in the dramatically decreased activity of the catalyst, while negligible conversion of phenols ( 2 and $7 \%$ after 1300 min of TOS for phenol and 2-naphthol, respectively) was found over $\mathrm{Fe}(\mathrm{BTC})$, characterized by a less ordered framework.
\end{abstract}

Keywords: metal-organic frameworks, acidity, annulation, prenylation

\section{Introduction}

The 2,2-dimethylbenzopyran unit is frequently present in many natural compounds exhibiting anti-HIV[1, 2], antihypertensive [3, 4] or antifeedant [5] activity. Antimycobacterial benzofurochroman [6], HIV inhibitory benzotripyrans [1] are typical examples. Several pharmaceuticals such as antioxidant vitamin E [7], antitumour clusifoliol [8] and anti-diabetic troglitazone [9] also possess the benzopyran moiety.

Both homogeneous and heterogeneous catalysts $\left(\mathrm{H}_{3} \mathrm{PO}_{4}\right.$ [10], $\mathrm{HCOOH}$ [11], $\mathrm{H}_{2} \mathrm{SO}_{4}$ [12], $\mathrm{HCl} / \mathrm{AlCl}_{3}$ [13], $\mathrm{BF}_{3} \cdot$ OEt [14], Montmorillonite KSF clay [15], Bi(OTf) ${ }_{3}$ [16-18], Amberlyst 15 
[19], zeolite HSZ-360 [20]) possessing Lewis and/or Brønsted acid centers were shown to produce 2,2-dimethylchromans through subsequent $\mathrm{C}$-isoprenylation of phenols with isoprene or 2-methyl-3-buten-2-ol (MBO) resulting in formation of 2- and 4-isoprenylphenols followed by intramolecular cyclization of prenylated product (Scheme 1) with the formation of target derivatives of 3,4-dihydro-2H-1-benzopyran (chromane) [21]. Formation of the more stabilized carbocation of the 2-prenylphenol and attack by the oxygen of the phenolic $\mathrm{OH}$ group result in the formation of the six- and not the five-membered ring [21].
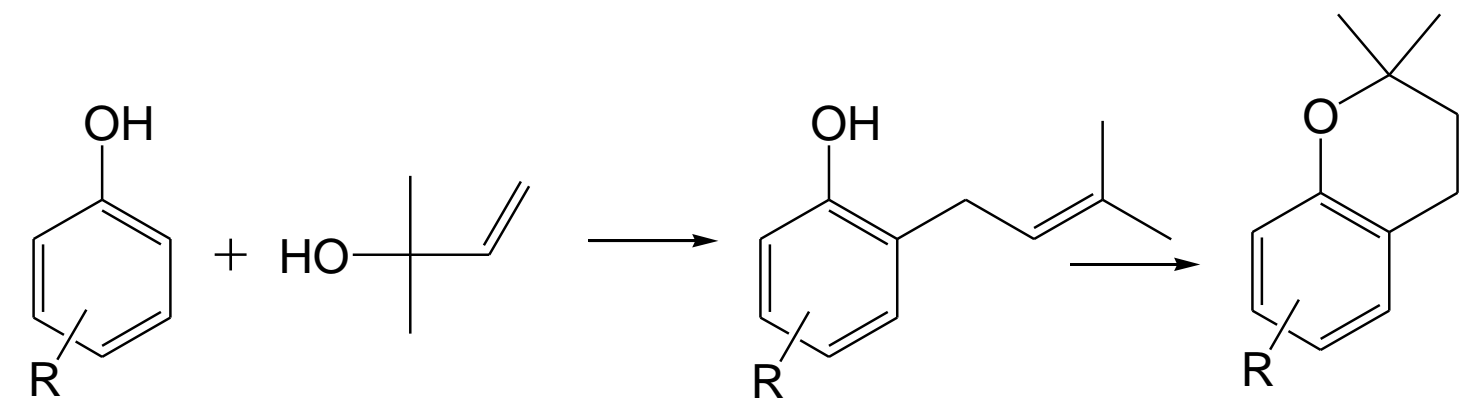

Scheme 1. Annulation of phenols with isoprene or 2-methyl-3-buten-2-ol.

MOFs represent crystalline hybrid organic-inorganic nanoporous materials with a quite high thermal stability [22, 23], adjustable chemical functionality [24], and extra-high porosity [25]. They are considered as one of the most fascinating classes of porous materials due to their potential in optoelectronic devices [26] and sensors [27], storage and separation of gases [28], medical imaging and drug delivery [29-34] and more recently emerging as highly interesting catalytic materials [35-37]. The presence of coordinatively unsaturated metalsites in some MOFs allows their application in catalysis as Lewis acids. MOFs can efficiently catalyze e.g. Friedländer condensation [38], Knoevenagel condensation [39-43], Huisgen cycloaddition [44], selective oxidation of cycloalkanes [45], and Friedel-Crafts benzylation [46].

Recently, we reported the catalytic benefits of $\mathrm{Cu}_{3}(\mathrm{BTC})_{2}$ and $\mathrm{Fe}(\mathrm{BTC}) \quad(\mathrm{BTC}=1,3,5-$ benzenetricarboxylate) over large-pore aluminosilicate zeolites Beta and USY in Pechmann condensation of 1-naphthol [47], Beckmann rearrangement of bulky camphor oxime [48], Prins reaction of paraformaldehyde and $\beta$-pinene [49] originating from mild acidity, the regularity in the arrangement of active sites within the framework and preferences in pore size of corresponding MOFs.

Although MOFs appear to be promising solid catalysts for the liquid-phase annulation reaction, to the best of our knowledge, there are no reports on the catalytic performance of MOFs in this reaction. In this contribution, we investigate the catalytic behavior of Fe-containing MOFs of different structures, namely Fe(BTC), MIL-100 (Fe), and compare it with MIL-100(Cr), and 
$\mathrm{Cu}_{3}(\mathrm{BTC})_{2}$ in annulation reaction between 2-methyl-3-buten-2-ol and phenols differing in size (phenol, 2-naphthol).

\section{Experimental}

\section{Materials}

$\mathrm{Cu}_{3}(\mathrm{BTC})_{2}$ (Basolite $\mathrm{C} 300$ ) and $\mathrm{Fe}(\mathrm{BTC})$ (Basolite F300) were purchased from Sigma Aldrich.

Iron(III) trimesate MIL-100(Fe) and chromium(III) trimesate MIL-100(Cr) were synthesized according to the literature $[50,51]$. MIL-100(Fe) was prepared by mixing metallic iron $(8.0$ mmol, 0.45g), 1,3,5-benzenetricarboxylic acid (5.4 mmol, $1.13 \mathrm{~g}), 5 \mathrm{M} \mathrm{HF}$ (16 mmol, $3.2 \mathrm{ml})$, and $1 \mathrm{M} \mathrm{HNO}_{3}(4.8 \mathrm{mmol}, 4.8 \mathrm{ml})$ in deionized water $(2.22 \mathrm{~mol}, 40 \mathrm{ml})$. The mixture was heated at $160{ }^{\circ} \mathrm{C}$ for $24 \mathrm{~h}$. The solid product was recovered by filtration and washed out with deionized water.

For the synthesis of MIL-100(Cr), metallic chromium (10 mmol, $0.52 \mathrm{~g})$ was dispersed into an aqueous solution of $5 \mathrm{M} \mathrm{HF}(20 \mathrm{mmol}, 4 \mathrm{ml})$. Then, trimesic acid $(6.7 \mathrm{mmol}, 1.41 \mathrm{mg})$ and $\mathrm{H}_{2} \mathrm{O}(2.67 \mathrm{~mol}, 48 \mathrm{~mL})$ were added and the mixture was heated at $220{ }^{\circ} \mathrm{C}$ for $48 \mathrm{~h}$. The resulting green powder was washed out with deionized water and acetone and dried in air.

2-Methyl-3-buten-2-ol ( $\geq 98 \%$ ), phenol ( $\geq 99 \%)$, 1- ( $\geq 99 \%)$, and 2-naphthol (98\%) were used as substrates, mesitylene $(\geq 99 \%)$ as internal standard, 1,2-dichloroethane ( $\geq 99 \%)$ as solvent in catalytic experiments. All reactants and solvents were obtained from Sigma Aldrich and used as received without any further treatment.

\section{Characterization}

The crystallinity of samples under study was determined by X-ray powder diffraction on a Bruker AXS D8 Advance diffractometer with a Vantec-1 detector in the Bragg-Brentano geometry using $\mathrm{CuK} \alpha$ radiation. A gentle grinding of the samples was performed before measurements.

The shape and size of crystals were determined by scanning electron microscopy (SEM; Jeol, JSM-5500LV).

Adsorption isotherms of nitrogen at $-196{ }^{\circ} \mathrm{C}$ were recorded using an ASAP 2020 (Micromeritics) static volumetric apparatus. Before adsorption experiments, the samples were degassed under turbomolecular pump vacuum at the temperature of $150{ }^{\circ} \mathrm{C}$. This temperature was maintained for $8 \mathrm{~h}$.

Determination of Lewis acid sites in MOFs is discussed in detail in our recent paper [52]. 


\section{Catalysis}

Annulation reaction between 2-methyl-3-buten-2-ol (MBO) and phenols (phenol, 2-naphthol) was performed in a liquid phase under atmospheric pressure and at reaction temperature $80{ }^{\circ} \mathrm{C}$ in a multi-experiment work station StarFish. Before catalytic experiments, $200 \mathrm{mg}$ of the catalyst was activated at $150{ }^{\circ} \mathrm{C}$ for $90 \mathrm{~min}$ with a temperature heating rate $10{ }^{\circ} \mathrm{C} / \mathrm{min}$. Typically, $3 \mathrm{mmol}$ of phenol, $0.4 \mathrm{~g}$ of mesitylene (internal standard), $200 \mathrm{mg}$ of catalyst and $10 \mathrm{ml}$ of 1,2dichloroethane (solvent) were added to the three-necked vessel, equipped with condenser and thermometer, stirred and heated. When the desired reaction temperature was reached, $4.5 \mathrm{mmol}$ of $\mathrm{MBO}$ was added into the reaction vessel through. $0.2 \mathrm{ml}$ of the reaction mixture was sampled using syringe with needle after 20,60, 120, 180, 300 and $1300 \mathrm{~min}$.

To evaluate a potential influence of leaching of active species from the heterogeneous catalysts, a part of the reaction mixture was filtered at the reaction temperature and the obtained liquid phase was further investigated in condensation reaction under the same reaction conditions.

The reaction products were analyzed by gas chromatography (GC) using an Agilent 6850 with FID detector equipped with a nonpolar HP1 column (diameter $0.25 \mathrm{~mm}$, thickness $0.2 \mu \mathrm{m}$ and length $30 \mathrm{~m}$ ). The reaction products were identified using GC-MS analysis (ThermoFinnigan, FOCUS DSQ II Single Quadrupole GC/MS).

\section{Results and Discussion}

\section{Structure and textural properties of MOFs}

The frameworks of MOFs under investigation are schematically depicted in Fig 1. In $\mathrm{Cu}_{3}(\mathrm{BTC})_{2}$ the $\mathrm{Cu}^{2}$-clusters are coordinated via carboxylate groups of benzene-1,3,5tricarboxylate to form a paddlewheel unit in a three-dimensional porous cubic network (Fig. 1). $\mathrm{Cu}_{3}(\mathrm{BTC})_{2}$ is a rigid MOF with a zeolite-like structure and with free coordination sites on the $\mathrm{Cu}^{\text {II }}$ ion. It contains three types of pores, of which the larger two penetrate the structure in all three dimensions and are connected with pore windows of ca. $6 \AA$ in diameter. The free coordination sites are oriented towards the center of one of the larger pore types [53]. MIL100(Fe) and MIL-100(Cr) are built up from trimers of $\mu 3$-oxo bridged iron(III)/chromium(III) oxide octahedra and 1,3,5-benzenetricarboxylate linkers resulting in hybrid supertetrahedra that further assemble into zeotypic mesoporous material with mesoporous cages [51] (Fig. 1). The crystal structure of $\mathrm{Fe}(\mathrm{BTC})$ still remains unknown. 

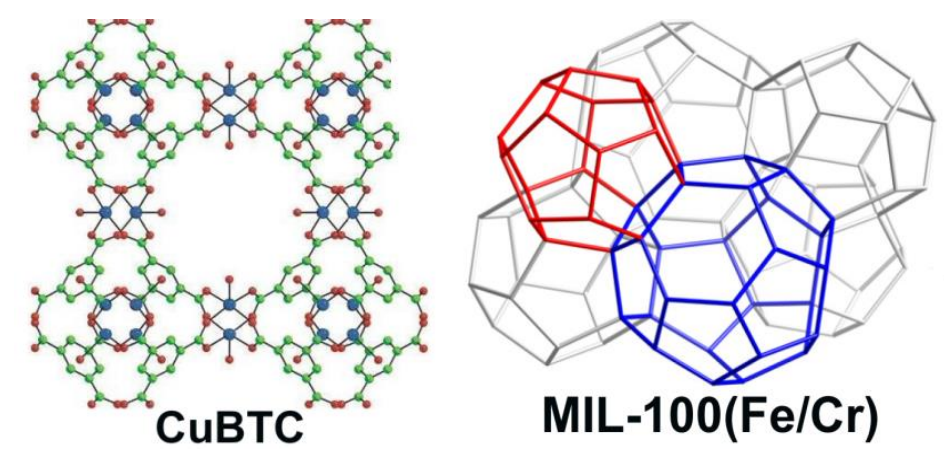

Figure 1. Frameworks of $\mathrm{Cu}_{3}(\mathrm{BTC})_{2}$, MIL-100(Fe/Cr).

XRD patterns of studied MOFs showed characteristic diffraction lines well-corresponding to the literature data (Fig. 2). No diffraction lines, attributable to additional phases, were observed. While $\mathrm{Cu}_{3}(\mathrm{BTC})_{2}, \mathrm{MIL}-100(\mathrm{Fe})$, and MIL-100(Cr) were found to be highly crystalline, $\mathrm{Fe}(\mathrm{BTC})$ represents less ordered material.

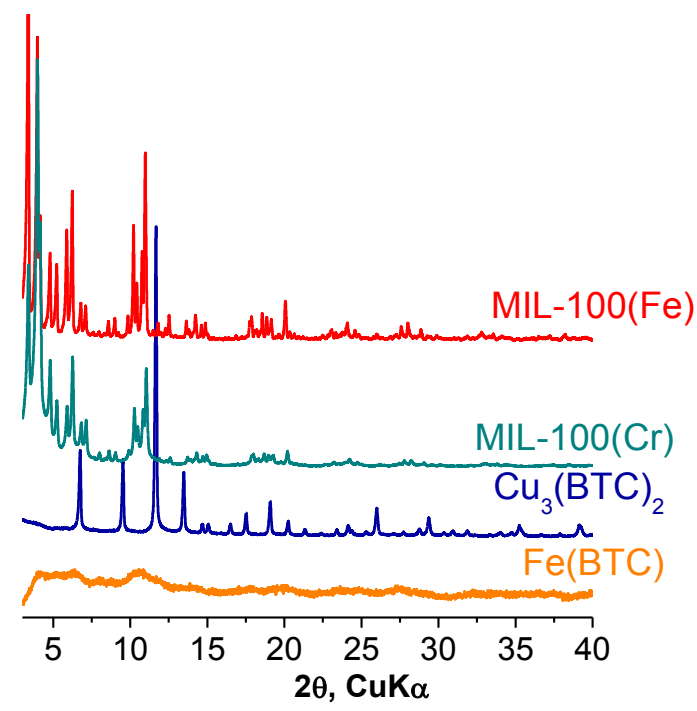

Figure 2.XRD patterns of MOFs.

The crystals of $\mathrm{Cu}_{3}(\mathrm{BTC})_{2}$ are rectangular prisms with the length of the edges of about $7 \mu \mathrm{m}$ while the size of the crystals of Fe(BTC) is about $3 \mu \mathrm{m}$ (Fig. SI1, Table 1). MIL-100(Fe) and MIL-100(Cr) showed rectangular crystals of 0.5 and $1 \mu \mathrm{m}$ in size. 

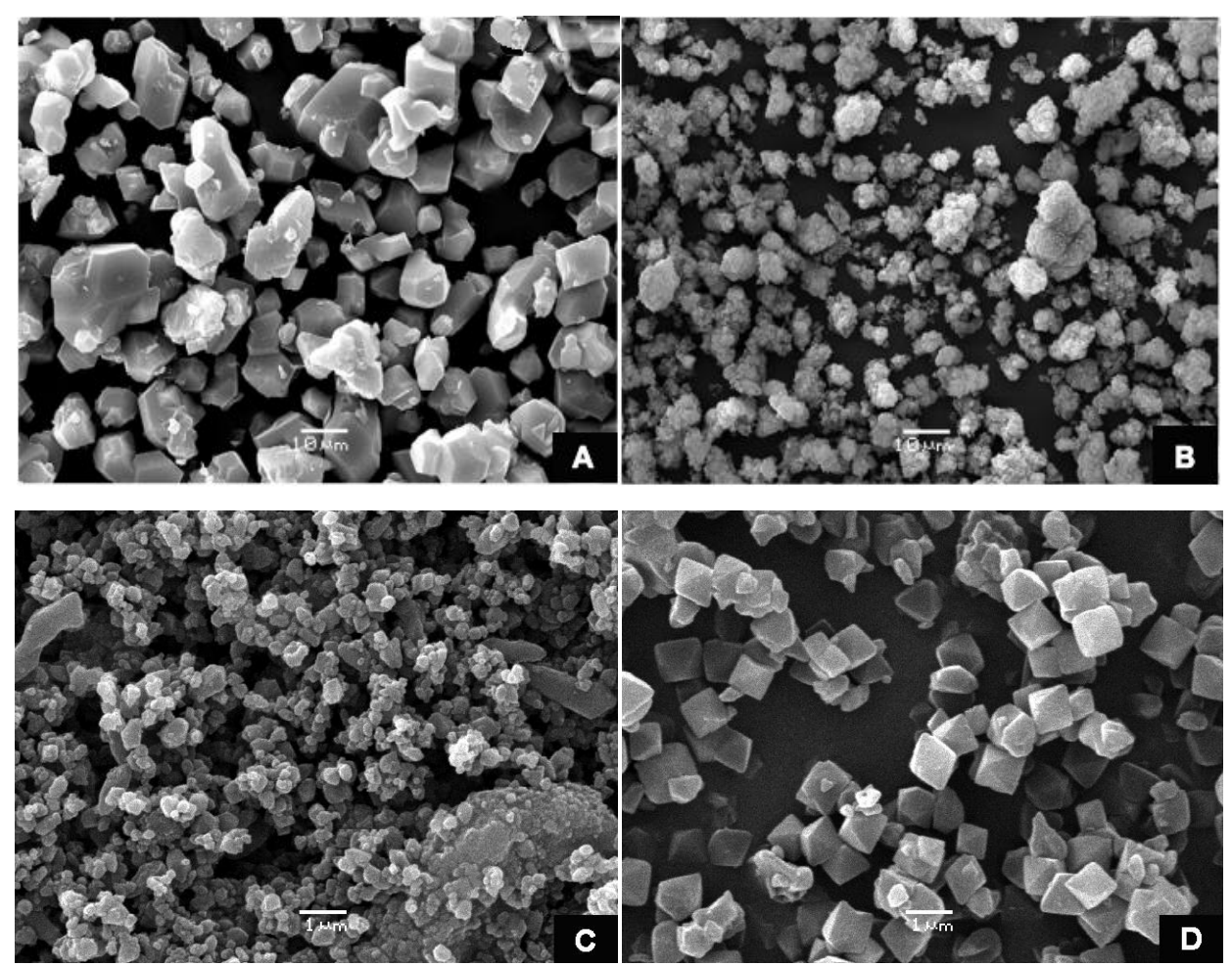

FigureSI1. SEM images of MOFs: $\mathrm{Cu}_{3}(\mathrm{BTC})_{2}$ (A), $\mathrm{Fe}(\mathrm{BTC})(\mathrm{B}), \mathrm{MIL}-100(\mathrm{Fe})(\mathrm{C})$, MIL$100(\mathrm{Cr})(\mathrm{D})$.

All MOFs under investigation show a type $\mathrm{I}$ isotherm, which is typical for materials possessing micropores (Fig. 3). However, as the porosity of MIL-100 originates from both $25 \AA$ and $29 \AA$ mesopores, which are accessible via $5.5 \AA$ and $8.6 \AA$ windows [54], two secondary uptakes at ca. $\mathrm{P} / \mathrm{P} 0=0.06$ and 0.12 can be distinguished from the isotherms of MIL-100(Fe) and MIL-100(Cr). Textural properties of all catalysts are summarized in Table 1. While all MOFs under investigation possess micropores of close size, the micropore volume increases in the sequence $\mathrm{Fe}(\mathrm{BTC})<\mathrm{Cu}_{3}(\mathrm{BTC})_{2}<\mathrm{MIL}-100(\mathrm{Cr}) \approx \mathrm{MIL}-100(\mathrm{Fe})$. The textural properties of the MIL-100 (Fe) and MIL-100 (Cr) materials do not differ substantially while less ordered Fe(BTC) is characterized by lower micropore volume and $\mathrm{S}_{\mathrm{BET}}$ surface area in comparison with $\mathrm{Cu}_{3}(\mathrm{BTC})_{2}$. 


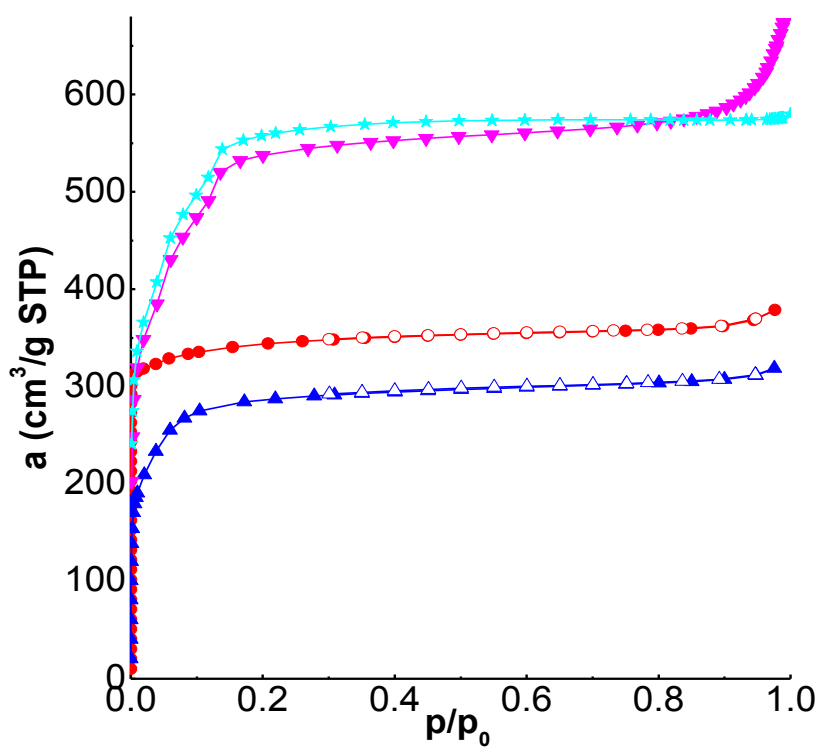

Figure 3. $\mathrm{N}_{2}$ adsorption isotherms of the catalysts: $\mathrm{Fe}(\mathrm{BTC})(-\boldsymbol{\Delta}-), \mathrm{Cu}_{3}(\mathrm{BTC})_{2}(--), \mathrm{MIL}-100$

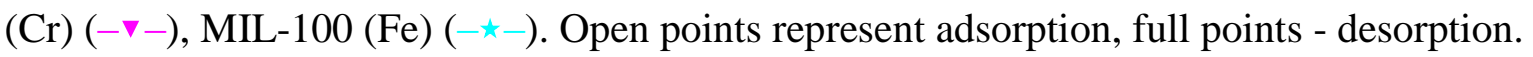

Table 1. Structural properties of used catalysts.

\begin{tabular}{|c|c|c|c|c|c|}
\hline Catalyst & $\underset{\mu \mathrm{m}}{\text { Crystal }} \operatorname{size}^{[\mathrm{a}]}$, & $\mathrm{S}_{\mathrm{BET}}{ }^{[\mathrm{b}]}, \mathrm{m}^{2} / \mathrm{g}$ & $\mathrm{D}_{\text {micro }}{ }^{[\mathrm{b}]}, \mathrm{nm}$ & $\mathrm{V}_{\text {micro }}{ }^{[\mathrm{b}]}, \mathrm{cm}^{3} / \mathrm{g}$ & $\begin{array}{l}\text { Lewis acid centers }{ }^{[\mathrm{c}]}[\mathrm{mmol} \\
\left.\mathrm{g}^{-1}\right]\end{array}$ \\
\hline $\mathrm{Cu}_{3}(\mathrm{BTC})_{2}$ & 7 & 1500 & 0.90 & 0.64 & 2.3 \\
\hline $\mathrm{Fe}(\mathrm{BTC})$ & 3 & 1060 & 0.86 & 0.33 & 1.6 \\
\hline MIL-100(Fe) & $\underline{0.5}$ & 2250 & 0.86 & 0.90 & n.d. ${ }^{[\mathrm{d}]}$ \\
\hline MIL-100(Cr) & $\underline{1.05}$ & 2030 & 0.86 & 0.83 & n.d. \\
\hline
\end{tabular}

[a] according to SEM images. [b] according to adsorption / desorption isotherms of $\mathrm{N}_{2}$. [c] according to IR of adsorbed pyridine, $[\mathrm{d}]$ not determined

The investigations of Lewis acidity of MOFs [55, 56] and demonstration of correlations between amount of Lewis acid sites and catalytic activity of MOFs [57] are rather limited.

The absorption band at $v=1069 \mathrm{~cm}^{-1}$ assigned to $\mathrm{C}-\mathrm{C}$ out-of-plane vibration in the pyridine molecule was chosen as the diagnostic band to evaluate the concentration of Lewis acid sites in $\mathrm{Cu}_{3}(\mathrm{BTC})_{2}$ and $\mathrm{Fe}(\mathrm{BTC})$. The concentration of coordinatively bonded pyridine is equal to 2.30 and $1.90 \mathrm{mmol} / \mathrm{g}$ for $\mathrm{Cu}_{3}(\mathrm{BTC})_{2}$ and $\mathrm{Fe}(\mathrm{BTC})$ activated at $473 \mathrm{~K}$, respectively.

Rustad et al. [58] estimated the acid strength of $\mathrm{Al}(\mathrm{III}), \mathrm{Cr}(\mathrm{III})$, and $\mathrm{Fe}(\mathrm{III}) \mu 3$-hydroxo functional groups from $a b$ initio electronic structure calculations. It was found that $=\mathrm{Fe}_{3} \mathrm{OH}$ and $=\mathrm{Al}_{3} \mathrm{OH}$ groups have nearly the same strength, while $=\mathrm{Cr}_{3} \mathrm{OH}$ groups appeared to be stronger ones. The ratio between metal charge and its ionic radius (e/r) can be used as an approximate 
measure for evaluation of a hardness of metal cations as acid sites [59]. From this point of view the hardness of Lewis acid centers increases in the following sequence: $\mathrm{Cu}^{2+}(\mathrm{e} / \mathrm{r}=2.73)<\mathrm{Fe}^{3+}$ $(\mathrm{e} / \mathrm{r}=4.65)<\mathrm{Cr}^{3+}(\mathrm{e} / \mathrm{r}=4.87)$.

\section{Catalytic behavior}

The conversion of investigated phenols in annulation reaction with $\mathrm{MBO}$ over MOF catalysts was found to increase in the following: MIL-100(Cr) $<\mathrm{Fe}(\mathrm{BTC})<<\mathrm{Cu}_{3}(\mathrm{BTC})_{2}<\mathrm{MIL}-100(\mathrm{Fe})$. It should be pointed out, that the highest conversions (45 and $75 \%$ after $1300 \mathrm{~min}$ of TOS for phenol and 2-naphthol, respectively, Fig. 4) were achieved over MIL-100(Fe) possessing the highest $\mathrm{V}_{\text {micro }}$ and $\mathrm{S}_{\mathrm{BET}}$ area (Table 1). At the same time, the increasing strength of Lewis acid centers for MIL-100(Cr) in comparison with MIL-100(Fe) $[58,60]$ results in the dramatic loss of the activity of the catalyst. This result is presumably caused by strong adsorption of phenol substrates on relatively strong Lewis acid centers of MIL-100(Cr). MIL-100(Fe) characterized by larger surface area and higher pore volume appeared to be more active in comparison with $\mathrm{Cu}_{3}(\mathrm{BTC})_{2}$ (45 vs 20 and 75 vs $60 \%$ after $1300 \mathrm{~min}$ of TOS for phenol and 2-naphthol, respectively). The last result may also be caused by the relative weakness of the $\mathrm{Cu}^{2+}$ acid sites for the activation of substrates. If the metal cation is a weak Lewis acid, the intermediate catalyst-substrate complex is unstable. On the other hand, if the metal cation is very acidic, the formed complex is too stable to undergo further reaction. Therefore, MOFs having metal cations with intermediate Lewis acidity provide the highest catalytic activity.

Surprisingly, the negligible conversion of phenols (2 and $7 \%$ after $1300 \mathrm{~min}$ of TOS for phenol and 2-naphthol, respectively) was found for Fe(BTC) possessing Fe Lewis acid centers.
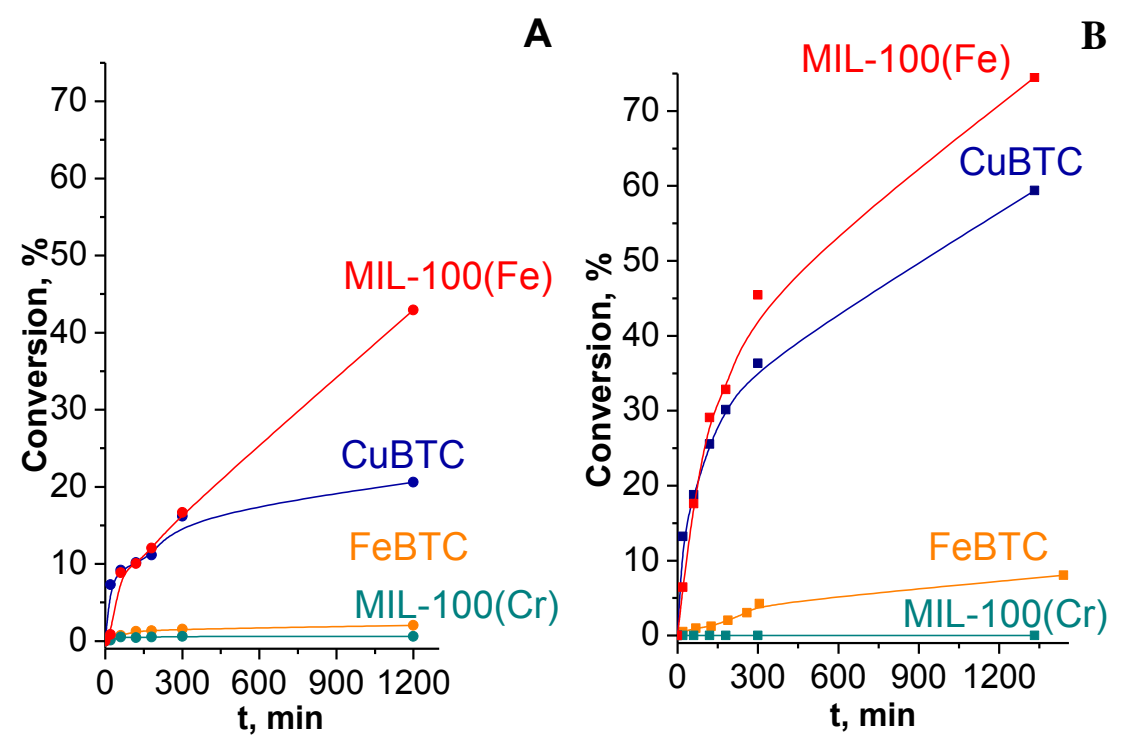
Figure 4. TOS dependence of phenol (A) and 2-naphthol (b) conversion in annulation with MBO over MOFs.

Limited confinement space for reactants in less ordered Fe(BTC) framework may be the reason of its poor catalytic behavior in annulation of phenols, involving bulky intermediate.

The reactivity of 2-naphthol in annulation with $\mathrm{MBO}$ over $\mathrm{Cu}_{3}(\mathrm{BTC})_{2}$ and MIL-100 (Fe) was found to be higher in comparison with phenol (Fig. 5), which is in agreement with Ref. [61]. Respective prenylphenols (PP, Fig. 5a,d) - the products of phenol and 2-naphthol prenylation with MBO, targeting 2,2-dimethylbenzopyranes (DMBP, Fig. 5b,e) and the products of their thermal rearrangement [62, 63] 2,2,3-trimethylbenzofuranes(TMBF, Fig. 5c,f) were detected in the reaction mixtures. The side-product of MBO oxidative dimerisation was found as well.

A<smiles>CC(C)=CCc1cccc(O)c1</smiles>

D<smiles>CC(C)=CCc1ccc2ccccc2c1</smiles>

B<smiles>CC1(C)CCc2ccccc2O1</smiles>

E<smiles>CC1(C)CCc2cc3ccccc3cc2O1</smiles><smiles>Cc1cccc2c1OC(C)(C)C2C</smiles>

$\mathbf{F}$<smiles>CC1c2cc3ccccc3cc2OC1(C)C</smiles>

Figure 5. Isomeric products observed during annulation of phenol $(a, b, c$,$) and 2-naphthol (d, e,$ f).

Figure 6 shows that the product distribution depends on the type of metal in MOF. The relative amount of intermediate PP (Fig. 5a,d) is higher for $\mathrm{Cu}_{3}(\mathrm{BTC})_{2}(22$ vs $6 \%$ in the case of phenol annulation over $\mathrm{Cu}_{3}(\mathrm{BTC})_{2}$ and $\mathrm{MIL}-100(\mathrm{Fe})$, respectively), while the products of consequent intramolecular cyclization DMBP (Fig. 5b,e) were mainly observed over MIL-100 (Fe). This result may indicate a higher rate of consecutive annulation over MIL-100 (Fe) in comparison with $\mathrm{Cu}_{3}(\mathrm{BTC})_{2}$ and may be connected with a higher acid strength of the former catalyst. Relatively higher amount of TMBF ( Fig. 5c,f) produced over $\mathrm{Cu}_{3}(\mathrm{BTC})_{2}$ may also be caused by a lower rate of annulation producing substituted DMBP in comparison with the rate of thermally-induced rearrangement consuming it. 


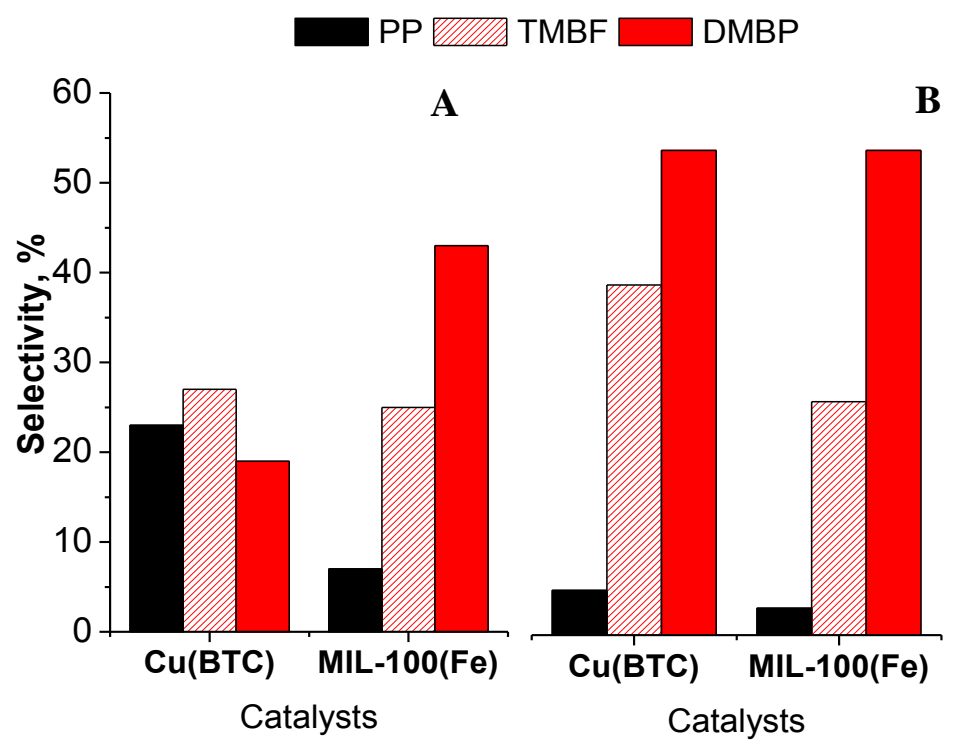

Figure 6.Selectivities to the products of annulation of phenol (A) and 2-naphthol (B) with MBO over MOFs at $16 \%$ of substrate conversion.

The preservation of the frameworks of the most active MIL-100(Fe) and $\mathrm{Cu}_{3}(\mathrm{BTC})_{2}$ catalysts under the conditions of 2-naphthol annulation reaction was confirmed by means of XRD (Fig. 7). In particular, we observed neither the significant changes of the intensity of individual diffraction lines, attributed to the respective interplanar distances of MIL-100(Fe) and $\mathrm{Cu}_{3}(\mathrm{BTC})_{2}$, nor their positions.
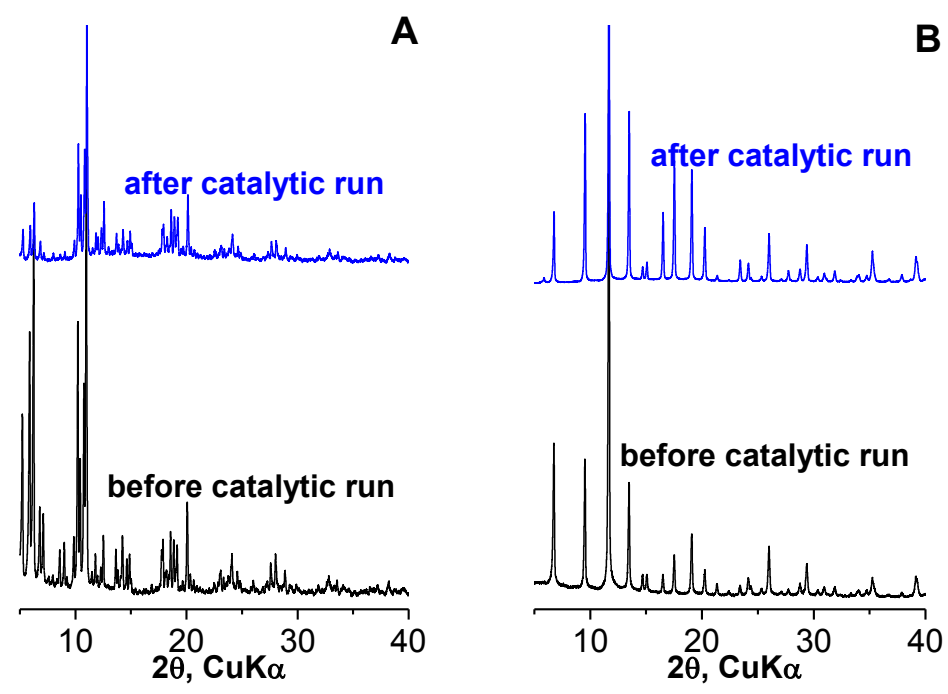

Figure 7. XRD patterns of MIL-100(Fe) (A) and $\mathrm{Cu}_{3}(\mathrm{BTC})_{2}(\mathrm{~B})$ before and after annulation of 2-naphthol with $\mathrm{MBO}\left(\mathrm{T}=80^{\circ} \mathrm{C}, 1,2\right.$-dichloroethane as solvent $)$.

The heterogeneous character of the reaction was evidenced in special experiments for the most active samples, MIL-100(Fe) and $\mathrm{Cu}_{3}(\mathrm{BTC})_{2}$. The respective catalysts were filtered off and 
centrifugated after $120 \mathrm{~min}$ of reaction in 1,2-dichloroethane at $80^{\circ} \mathrm{C}$. At that time, MIL-100(Fe) and $\mathrm{Cu}_{3}(\mathrm{BTC})_{2}$ achieved conversions of 2-naphthol about 30 and $25 \%$, respectively. Then, the filtrate without the catalyst was stirred at $80{ }^{\circ} \mathrm{C}$ for $1200 \mathrm{~min}$. After removing the catalyst, further increase in the conversion of 2-naphthol (0.8 and $0.9 \%$, respectively) was negligible, providing evidence of heterogeneous catalysis (Fig. 8).
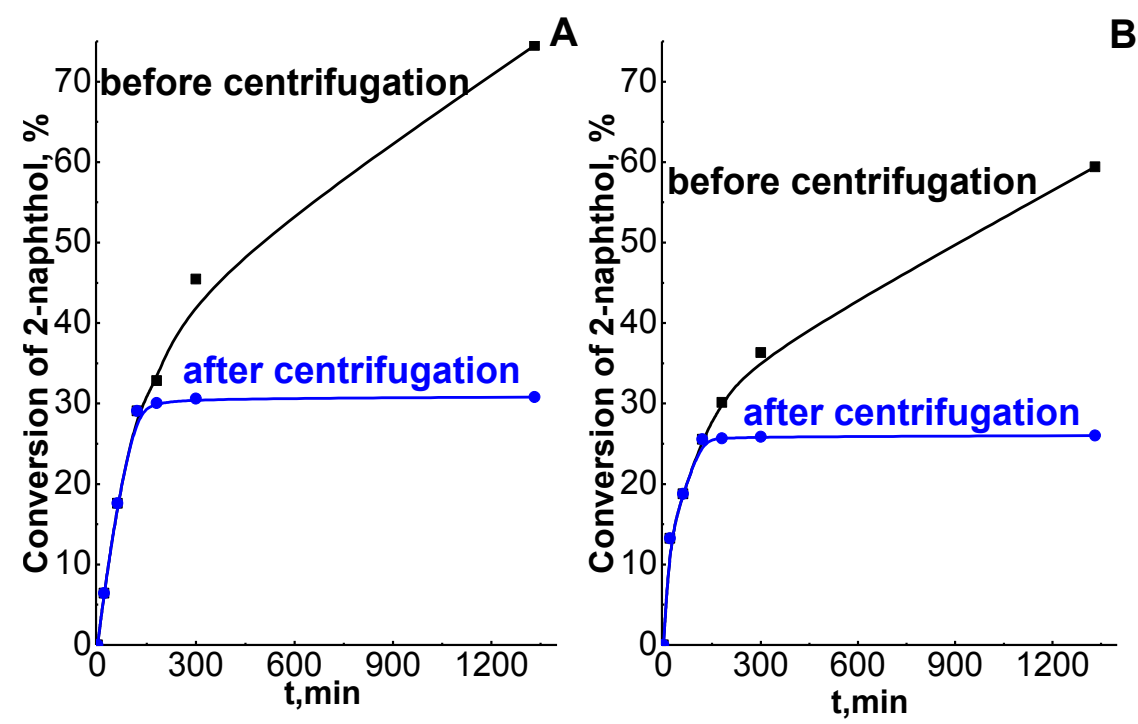

Figure 8. Leaching test of $\mathrm{Fe}^{3+}$ ions from $\mathrm{MIL}-100(\mathrm{Fe})(\mathrm{A})$ and $\mathrm{Cu}^{2+}$ ions from $\mathrm{Cu}_{3}(\mathrm{BTC})_{2}$ catalysts (B) under conditions of 2-naphthol annulation with $\mathrm{MBO}\left(\mathrm{T}=80{ }^{\circ} \mathrm{C}\right.$, 1,2dichloroethane as solvent, $3.0 \mathrm{mmol}$ of 2-naphthol, $4.5 \mathrm{mmol}$ of $\mathrm{MBO}, \mathrm{m}$ (catalyst) = $0.2 \mathrm{~g}$ ).

\section{Conclusions}

Catalytic behavior of $\mathrm{Cu}_{3}(\mathrm{BTC})_{2}, \mathrm{Fe}(\mathrm{BTC}), \mathrm{MIL}-100(\mathrm{Fe})$, and MIL-100 (Cr) was investigated in annulation of phenol and 2-naphthol with 2-methyl-3-buten-2-ol and related with acidic and textural properties of the catalyst. The highest conversions of phenols (45 and $75 \%$ after 1300 min of TOS for phenol and 2-naphthol, respectively) and selectivity to target chromane (42 and $56 \%$ at $16 \%$ conversion of phenol and 2-naphthol, respectively) were achieved over MIL-100 $(\mathrm{Fe})$ possessing intermediate Lewis acidity, perfect crystalline structure and highest $\mathrm{S}_{\mathrm{BET}}$ surface area. The highest acid strength of Lewis acid centers for MIL-100(Cr) was found to result in the dramatic decrease in the activity of the catalyst. While negligible conversion of phenols ( 2 and 7 $\%$ after $1300 \mathrm{~min}$ of TOS for phenol and 2-naphthol, respectively) was found over $\mathrm{Fe}(\mathrm{BTC})$ characterized by low ordered framework with a limited confinement space for the formation of quite bulky intermediate. The highest activity as well as the preservation of the structure and the active centers of MIL-100(Fe) make this MOF a promising catalyst for annulation reaction. 


\section{Acknowledgement}

M.O. and J.Č. acknowledge the Czech Science Foundation (14-07101S).

\section{References}

[1] Y. Kashman, K.R. Gustafson, R.W. Fuller, J.H. Cardellina, J.B. McMahon, M.J. Currens, R.W. Buckheit, S.H. Hughes, G.M. Cragg, M.R. Boyd, HIV Inhibitory natural products. 7. The calanolides, a novel HIV-inhibitory class of coumarin derivatives from the tropical rain-forest tree, Calophyllum-lanigerum, Journal of Medicinal Chemistry, 35 (1992) 2735-2743.

[2] M.J. Currens, J.M. Mariner, J.B. McMahon, M.R. Boyd, Kinetic analysis of inhibition of human immunodeficiency virus type-1 reverse transcriptase by calanolide A, Journal of Pharmacology and Experimental Therapeutics, 279 (1996) 652-661.

[3] R. Bergmann, R. Gericke, Synthesis and antihypertensive activity of 4-(1,2-dihydro-2-oxo-1pyridyl)-2H-1-benzopyrans and related-compounds, new potassium channel activators, Journal of Medicinal Chemistry, 33 (1990) 492-504.

[4] R. Gericke, J. Harting, I. Lues, C. Schittenhelm, 3-Methyl-2H-1-benzopyran potassium channel activators, Journal of Medicinal Chemistry, 34 (1991) 3074-3085.

[5] R.P. Srivastava, P. Proksch, Contact toxicity and feeding inhibitory activity of chromenes from Asteraceae against Spodoptera-littoralis (Lepidoptera, Noctuidae), Entomologia Generalis, 15 (1991) 265-274.

[6] S. Prado, H. Ledeit, S. Michel, M. Koch, J.C. Darbord, S.T. Cole, F. Tillequin, P. Brodin, Benzofuro-3,2-f 1 benzopyrans: A new class of antitubercular agents, Bioorganic \& Medicinal Chemistry, 14 (2006) 5423-5428.

[7] G.W. Burton, K.U. Ingold, Vitamin E - application of the principles of physical organic chemistry to the exploration of its structure and function, Accounts of Chemical Research, 19 (1986) 194-201.

[8] N.P. Seeram, H. Jacobs, S. McLean, W.F. Reynolds, A prenylated benzopyran derivative from Peperomia clusiifolia, Phytochemistry, 49 (1998) 1389-1391.

[9] K. Matsumoto, S. Miyake, M. Yano, Y. Ueki, Y. Tominaga, Increase of lipoprotein (a) with troglitazone, Lancet, 350 (1997) 1748-1749.

[10] V.K. Ahluwalia, K.K. Arora, R.S. Jolly, Acid-catalyzed condensation of isoprene with phenols - formation of 2,2-dimethylchromans, Journal of the Chemical Society-Perkin Transactions 1, (1982) 335-338.

[11] B. Pushpa, D. Rameshwar, Synthetic confirmation for the structure of stipulin, Indian journal of chemistry, 41 B (2002) 184-186.

[12] D.H. Charles, A.H. William, Directed ring closure in the synthesis of chromans and coumarans from o-allylphenols, Journal of Organic Chemistry, 5 (1940) 212-222.

[13] Y. Wang, J. Wu, P. Xia, Synthesis of 1,1-dimethyl-4-indanol derivatives, Synthetic Communications, 36 (2006) 2685-2698.

[14] T. Narender, K.P. Reddy, $\mathrm{BF}_{3}-\mathrm{Et}_{2} \mathrm{O}$ mediated biogenetic type synthesis of chromanochalcones from prenylated chalcones via a regioselective cyclization reaction, Tetrahedron Letters, 48 (2007) 7628-7632.

[15] W.G. Dauben, J.M. Cogen, V. Behar, Clay catalyzed rearrangement of substituted allyl 
phenyl ethers: Synthesis of ortho-allyl phenols, chromans and coumarans, Tetrahedron Letters, 31 (1990) 3241-3244.

[16] T. Ollevier, T.M. Mwene-Mbeja, Bismuth triflate catalyzed 1,3 rearrangement of aryl 3methylbut-2-enyl ethers, Synthesis-Stuttgart, (2006) 3963-3966.

[17] K.E. Judd, L. Caggiano, Bi(OTf $)_{3}$-catalysed prenylation of electron-rich aryl ethers and phenols with isoprene: a direct route to prenylated derivatives, Organic \& Biomolecular Chemistry, 9 (2011) 5201-5210.

[18] B. Sreedhar, V. Swapna, C. Sridhar, Bismuth(III) triflate: Novel and efficient catalyst for Claisen and Fries rearrangements of allyl ethers and phenyl esters, Synthetic Communications, 34 (2004) 1433-1440.

[19] G.P. Kalena, A. Jain, A. Banerji, Amberlyst 15 catalyzed prenylation of phenols: One-step synthesis of benzopyrans, Molecules, 2 (1997) 100-105.

[20] F. Bigi, S. Carloni, R. Maggi, C. Muchetti, M. Rastelli, G. Sartori, Reaction between phenols and isoprene under zeolite catalysis. Highly selective synthesis of chromans and o-isopentenylphenols, Synthesis-Stuttgart, (1998) 301-304.

[21] Synthetic and natural phenols, Elsevier, 1996.

[22] H. Li, M. Eddaoudi, M. O'Keeffe, O.M. Yaghi, Design and synthesis of an exceptionally stable and highly porous metal-organic framework, Nature, 402 (1999) 276-279.

[23] R.E. Morris, Metal-organic frameworks: Grown into shape, Nat Chem, 3 (2011) 347-348.

[24] M. Eddaoudi, J. Kim, N. Rosi, D. Vodak, J. Wachter, M. O'Keeffe, O.M. Yaghi, Systematic design of pore size and functionality in isoreticular MOFs and their application in methane storage, Science, 295 (2002) 469-472.

[25] H.K. Chae, D.Y. Siberio-Perez, J. Kim, Y. Go, M. Eddaoudi, A.J. Matzger, M. O'Keeffe, O.M. Yaghi, A route to high surface area, porosity and inclusion of large molecules in crystals, Nature, 427 (2004) 523-527.

[26] S. Ma, H.-C. Zhou, Gas storage in porous metal-organic frameworks for clean energy applications, Chemical Communications, 46 (2010) 44-53.

[27] S.M. Cohen, New approaches for medicinal applications of bioinorganic chemistry, Current Opinion in Chemical Biology, 11 (2007) 115-120.

[28] A. Corma, H. Garcia, F.X.L.I. Llabres i Xamena, Engineering Metal Organic Frameworks for Heterogeneous Catalysis, Chemical Reviews, 110 (2010) 4606-4655.

[29] A. Corma, State of the art and future challenges of zeolites as catalysts, Journal of Catalysis, 216 (2003) 298-312.

[30] N.J. Hinks, A.C. McKinlay, B. Xiao, P.S. Wheatley, R.E. Morris, Metal organic frameworks as NO delivery materials for biological applications, Microporous and Mesoporous Materials, 129 (2010) 330-334.

[31] A.C. McKinlay, B. Xiao, D.S. Wragg, P.S. Wheatley, I.L. Megson, R.E. Morris, Exceptional behavior over the whole adsorption-storage-delivery cycle for $\mathrm{NO}$ in porous metal organic frameworks, Journal of the American Chemical Society, 130 (2008) 1044010444.

[32] B. Xiao, P.S. Wheatley, X. Zhao, A.J. Fletcher, S. Fox, A.G. Rossi, I.L. Megson, S. Bordiga, L. Regli, K.M. Thomas, R.E. Morris, High-capacity hydrogen and nitric oxide adsorption and storage in a metal-organic framework, Journal of the American Chemical Society, 129 (2007) 1203-1209. 
[33] S. Bordiga, L. Regli, F. Bonino, E. Groppo, C. Lamberti, B. Xiao, P.S. Wheatley, R.E. Morris, A. Zecchina, Adsorption properties of HKUST-1 toward hydrogen and other small molecules monitored by IR, Physical Chemistry Chemical Physics, 9 (2007) 26762685 .

[34] A.C. McKinlay, R.E. Morris, P. Horcajada, G. Ferey, R. Gref, P. Couvreur, C. Serre, BioMOFs: Metal-Organic Frameworks for Biological and Medical Applications, Angewandte Chemie-International Edition, 49 (2010) 6260-6266.

[35] J. Lee, O.K. Farha, J. Roberts, K.A. Scheidt, S.T. Nguyen, J.T. Hupp, Metal-organic framework materials as catalysts, Chemical Society Reviews, 38 (2009) 1450-1459.

[36] A. Dhakshinamoorthy, M. Opanasenko, J. Čejka, H. Garcia, Metal Organic Frameworks as Solid Catalysts in Condensation Reactions of Carbonyl Groups, Advanced Synthesis \& Catalysis, 355 (2013) 247-268.

[37] A. Dhakshinamoorthy, M. Opanasenko, J. Cejka, H. Garcia, Metal organic frameworks as heterogeneous catalysts for the production of fine chemicals, Catalysis Science \& Technology, 3 (2013) 2509-2540.

[38] E. Perez-Mayoral, J. Cejka, $\mathrm{Cu}_{3}(\mathrm{BTC})_{2}$ : A Metal-Organic Framework Catalyst for the Friedlander Reaction, ChemCatChem, 3 (2011) 157-159.

[39] M. Opanasenko, A. Dhakshinamoorthy, M. Shamzhy, P. Nachtigall, M. Horacek, H. Garcia, J. Cejka, Comparison of the catalytic activity of MOFs and zeolites in Knoevenagel condensation, Catalysis Science \& Technology, 3 (2013) 500-507.

[40] S. Hasegawa, S. Horike, R. Matsuda, S. Furukawa, K. Mochizuki, Y. Kinoshita, S. Kitagawa, Three-dimensional porous coordination polymer functionalized with amide groups based on tridentate ligand: Selective sorption and catalysis, Journal of the American Chemical Society, 129 (2007) 2607-2614.

[41] M.K. Sharma, P.P. Singh, P.K. Bharadwaj, Two-dimensional rhombus grid coordination polymer showing heterogeneous catalytic activities, Journal of Molecular Catalysis aChemical, 342-43 (2011) 6-10.

[42] X.-M. Lin, T.-T. Li, L.-F. Chen, L. Zhang, C.-Y. Su, Two ligand-functionalized Pb(II) metalorganic frameworks: structures and catalytic performances, Dalton Transactions, 41 (2012) 10422-10429.

[43] M. Hartmann, M. Fischer, Amino-functionalized basic catalysts with MIL-101 structure, Microporous and Mesoporous Materials, 164 (2012) 38-43.

[44] I. Luz, F.X. Llabres i Xamena, A. Corma, Bridging homogeneous and heterogeneous catalysis with MOFs "Click" reactions with $\mathrm{Cu}-\mathrm{MOF}$ catalysts, Journal of Catalysis, 276 (2010) 134-140.

[45] F.X. Llabres i Xamena, O. Casanova, R. Galiasso Tailleur, H. Garcia, A. Corma, Metal organic frameworks (MOFs) as catalysts: A combination of $\mathrm{Cu}^{2+}$ and $\mathrm{Co}^{2+} \mathrm{MOF}$ as an efficient catalyst for tetralin oxidation, Journal of Catalysis, 255 (2008) 220-227.

[46] P. Horcajada, S. Surble, C. Serre, D.-Y. Hong, Y.-K. Seo, J.-S. Chang, J.-M. Greneche, I. Margiolaki, G. Ferey, Synthesis and catalytic properties of MIL-100(Fe), an iron(III) carboxylate with large pores, Chemical Communications, (2007) 2820-2822.

[47] M. Opanasenko, M. Shamzhy, J. Cejka, Solid Acid Catalysts for Coumarin Synthesis by the Pechmann Reaction: MOFs versus Zeolites, Chemcatchem, 5 (2013) 1024-1031.

[48] M. Opanasenko, M. Shamzhy, M. Lamac, J. Cejka, The effect of substrate size in the Beckmann rearrangement: MOFs vs. zeolites, Catalysis Today, 204 (2013) 94-100. 
[49] M. Opanasenko, A. Dhakshinamoorthy, Y.K. Hwang, J.-S. Chang, H. Garcia, J. Cejka, Superior Performance of MetalOrganic Frameworks over Zeolites as Solid Acid Catalysts in the Prins Reaction: Green Synthesis of Nopol, Chemsuschem, 6 (2013) 865-871.

[50] J.W. Yoon, Y.-K. Seo, Y.K. Hwang, J.-S. Chang, H. Leclerc, S. Wuttke, P. Bazin, A. Vimont, M. Daturi, E. Bloch, P.L. Llewellyn, C. Serre, P. Horcajada, J.-M. Greneche, A.E. Rodrigues, G. Ferey, Controlled Reducibility of a Metal-Organic Framework with Coordinatively Unsaturated Sites for Preferential Gas Sorption, Angewandte ChemieInternational Edition, 49 (2010) 5949-5952.

[51] G. Ferey, C. Serre, C. Mellot-Draznieks, F. Millange, S. Surble, J. Dutour, I. Margiolaki, A hybrid solid with giant pores prepared by a combination of targeted chemistry, simulation, and powder diffraction, Angewandte Chemie-International Edition, 43 (2004) 6296-6301.

[52] E. Perez-Mayoral, Z. Musilova, B. Gil, B. Marszalek, M. Polozij, P. Nachtigall, J. Cejka, Synthesis of quinolines via Friedlander reaction catalyzed by CuBTC metal-organicframework, Dalton Transactions, 41 (2012) 4036-4044.

[53] S.S.Y. Chui, S.M.F. Lo, J.P.H. Charmant, A.G. Orpen, I.D. Williams, A chemically functionalizable nanoporous material $\mathrm{Cu}_{3}(\mathrm{TMA})_{2}(\mathrm{H} 2 \mathrm{O})_{3 \mathrm{n}}$, Science, 283 (1999) 11481150 .

[54] N.A. Khan, J.S. Lee, J. Jeon, C.-H. Jun, S.H. Jhung, Phase-selective synthesis and phaseconversion of porous aluminum-benzenetricarboxylates with microwave irradiation, Microporous and Mesoporous Materials, 152 (2012) 235-239.

[55] H. Leclerc, A. Vimont, J.-C. Lavalley, M. Daturi, A.D. Wiersum, P.L. Llwellyn, P. Horcajada, G. Ferey, C. Serre, Infrared study of the influence of reducible iron(III) metal sites on the adsorption of $\mathrm{CO}, \mathrm{CO}_{2}$, propane, propene and propyne in the mesoporous metal-organic framework MIL-100, Physical Chemistry Chemical Physics, 13 (2011) 11748-11756.

[56] A. Vimont, J.M. Goupil, J.C. Lavalley, M. Daturi, S. Surble, C. Serre, F. Millange, G. Ferey, $\mathrm{N}$. Audebrand, Investigation of acid sites in a zeotypic giant pores chromium(III) carboxylate, Journal of the American Chemical Society, 128 (2006) 3218-3227.

[57] L. Alaerts, E. Seguin, H. Poelman, F. Thibault-Starzyk, P.A. Jacobs, D.E. De Vos, Probing the Lewis acidity and catalytic activity of the metal-organic framework $\mathrm{Cu}_{3}(\mathrm{btc})_{2}(\mathrm{BTC}=$ benzene-1,3,5-tricarboxylate), Chemistry-a European Journal, 12 (2006) 7353-7363.

[58] J.R. Rustad, D.A. Dixon, A.R. Felmy, Intrinsic acidity of aluminum, chromium (III) and iron (III) m3-hydroxo functional groups from ab initio electronic structure calculations, Geochimica Et Cosmochimica Acta, 64 (2000) 1675-1680.

[59] J.C. Penzien, C. Haessner, A. Jentys, K. Kohler, T.E. Muller, J.A. Lercher, Heterogeneous catalysts for hydroamination reactions: structure-activity relationship, Journal of Catalysis, 221 (2004) 302-312.

[60] M.N. Timofeeva, V.N. Panchenko, A.A. Abel, N.A. Khan, I. Ahmed, A.B. Ayupov, K.P. Volcho, S.H. Jhung, Rearrangement of $\alpha$-pinene oxide to campholenic aldehyde over the trimesate metal-organic frameworks MIL-100, MIL-110 and MIL-96, Journal of Catalysis, 311 (2014) 114-120.

[61] L.A. Adrio, K.K. Hii, A recyclable copper(II) catalyst for the annulation of phenols with 1,3-dienes, Chemical Communications, (2008) 2325-2327.

[62] E.D. Weil, E. Leon, J. Linder, Thermal rearrangement of tetrachloro-2H-pyran-2-one to trichloro-2-furoyl chloride, Journal of Organic Chemistry, 26 (1961) 5185-\&. 
[63] D.N. Bobrov, A.S. Lyakhov, A.A. Govorova, V.I. Tyvorsky, Thermal rearrangement of acyloxy-substituted 2-trifluoromethyl-4H-pyran-4-ones into spiro-annelated $3(2 \mathrm{H})$ furanones, Khimiya Geterotsiklicheskikh Soedinenii, (2000) 1028-1034. 